\title{
Questionnaire Study on the Comparison among Circadian Typology, Sleep Habit, Physical and Mental Health and Meal Habit in Japanese University Athletes
}

\author{
Miyo Nakade1, Hitomi Takeuchi², Takuya Uezato², Milada Krejci³, \\ Fujiko Tsuji², Takahiro Kawada4, Teruki Noji ${ }^{4}$, Tetsuo Harada ${ }^{2 *}$ \\ ${ }^{1}$ Faculty of Health and Nutrition, Tokai-Gakuen University, Nagoya, Japan \\ ${ }^{2}$ Laboratory of Environmental Physiology, Graduate School of Integrated Arts and Sciences, Kochi University, \\ Kochi, Japan \\ ${ }^{3}$ University of Physical Education and Sports PALESTRA, Prague, Czech Republic \\ ${ }^{4}$ Center for Regional Collaboration, Kochi University, Kochi, Japan \\ Email: haratets@kochi-u.ac.jp
}

Received 20 January 2015; accepted 21 September 2015; published 24 September 2015

Copyright (C) 2015 by authors and Scientific Research Publishing Inc.

This work is licensed under the Creative Commons Attribution International License (CC BY).

http://creativecommons.org/licenses/by/4.0/

c) (i) Open Access

\section{Abstract}

It has been pointed out that Japanese university students have several problems from psychological and social points of view due to their evening-typed life. For university athletes, evening-typed life is afraid to promote reduced quality of performance and high risk to be injured during training and match. This study tries to investigate the relationship among circadian typology, sleep habit, physical and mental health and meal habit from epidemiological view point. An integrated questionnaire was administrated to 120 men athletes attending university soccer club in November 2013 and 62 ones answered it correctly. The questionnaire included the diurnal type scale which is constructed by Torsvall \& Åkerstedt (1980) and questions on sleep habits and mental health, SOC scale (SOC3- UTHS) and FFQ scale. Morning-typed students showed higher quality of sleep $(p=0.015)$ and they tended to have higher SOC scores $(p=0.071)$ than the other chronotypes. Evening-typed students took higher amount of carbohydrates than the other types $(p=$ 0.048). Circadian typology might be related to not only sleep health but also the nutritional characteristics and psychological responses to social stress in Japanese university athletes.

\footnotetext{
*Corresponding author.
}

How to cite this paper: Nakade, M., Takeuchi, H., Uezato, T., Krejci, M., Tsuji, F., Kawada, T., Noji, T., \& Harada, T. (2015). Questionnaire Study on the Comparison among Circadian Typology, Sleep Habit, Physical and Mental Health and Meal Habit in Japanese University Athletes. Psychology, 6, 1562-1569. http://dx.doi.org/10.4236/psych.2015.612153 


\section{Keywords}

\section{Athletes, Circadian Typology, Sleep Health, Resistance to Stress, Nutrition}

\section{Introduction}

Since 1980s, the sports nutrition boom has continued to produce many kinds of appealing products as supporting the nutrition consume by the athletes which contribute to the nutritional complete and improved performance to some extent (Ryan-Krause, 1998). For example, supplements made from milk are powerful for supporting athletes to intake protein which includes furosine, a well-known index for the availability of lysine (Rufián-Henares et al., 2007). Sports supplements made from milk were reported as "tryptophan" resource by Delgado-Andrade et al. (2006). However, the most important supply of nutrition for athletes is due to the meals, especially breakfast which is the key to serotonin and melatonin synthesis in the pineal of them (Harada et al., 2013a, b). Serotonin synthesis could be high concentration during the daytime exercise and melatonin synthesis would promote the sleep onset (Wada et al., 2010; Takeuchi et al., 2014; Wada et al., 2013). Nutritionally well balanced breakfast could be easily taken due to the change of the life of athletes from "evening-type" to "morning-type". However, there are few reports on the relationship between circadian type (chronotype) and sleep health and meal habits in the athletes.

Japanese university students are easy to become evening-typed and their sleep and meal habits tend to be in irregular manner, because there is little social limitation in life time for the university students. Evening-typed life has been reported to lead to several problems in psychological, psychiatric and social manners (Harada et al., 2012). University athletes have relationship between their circadian typology and several issues: for example, sports performance, injury during practice and recovery from that, concentration during game and fitness (Harada et al., 2013a; Harada, Wada et al. unpublished). However, it would be remained unclear how the circadian typology of athletes is related to their nutritional consumption which can be integrated with mental health and sleep quality. This study aims to clarify the relationship among the circadian typology, sleep habit, mental and physical health and meal habit in an integrated manner in Japanese university athletes from epidemiological view point.

\section{Methods}

\subsection{Participants}

An integrated questionnaire was administrated to 120 male students attending Kochi University soccer club in November 2013. Sixty two students of them answered the questionnaire correctly.

\subsection{Questionnaire and Procedure}

The questionnaire consisted of the Diurnal Type Scale constructed by Torsvall \& Akerstedt (1980) (Appendix 1), sleep habit questionnaire (GPS score: Appendix 2), University of Tokyo Health Sociology Version of the Sense of Coherence (SOC3 UTHS: Appendix 3) and questions on mental health (irritation, anger, out of emotional control and depression), and Food Frequency Questionnaire Based on Food Groups (FFQ) to know the amount of specific foods and nutrition taken at daily meals and to know weight of foods taken at daily meals and frequency to take. These values could be calculated based on "The foods intake list".

\subsection{Statistic Analysis}

For statistical analysis of the data $\left(\chi^{2}\right.$-test and Kruskal-Wallis-test), SPSS statistics version 12.0 (IBM cooperation) was used.

\subsection{Ethic Treatment}

The study followed the guidelines established by the Chronobiology International Journal for the conduct of research on human subjects (Portaluppi et al., 2010). Before administrating the questionnaires, each participant 
was given a written explanation and also spoken explanation that detailed the concepts and purposes of the study and stated that their answers would be used only for academic purposes. After the above explanation, all participants agreed completely with the proposal. The study was also permitted by the committee of Kochi University Soccer Club which carried out an ethical inspection of on the contents of the questionnaire.

\section{Results}

The distribution of the Diurnal Type Score (DTS) was shown in Figure 1. Around 50\% of the participants showing medium scores, remained around 25\% showing higher scores and 25\% lower score were defined as the medium type, the morning-type and the evening-type, respectively (Figure 1). Mean \pm SD of the diurnal type scale scores of university athletes was $15.37 \pm 3.57$. Morning-type group (DTS scores: $19.44 \pm 1.89$ ) showed significantly higher scores of sleep quality than the medium type $(15.07 \pm 1.11)$ and evening-type $(10.71 \pm 1.77)$ groups (Kruskal-Wallis test: $\chi^{2}$-value $=8.415, \mathrm{df}=2, p=0.015$ ) (Figure 2). Morning-type group tended to show higher scores of the Sense of Coherence (SOC scores) than the evening-typed one (Kruskal-Wallis test: $p=$ 0.071) (Figure 3).

The ratio to take breakfast of the morning-typed participants tended to be higher than that of the other two chrono-types $\left(\chi^{2}\right.$-test, $\chi^{2}$-value $\left.=4.37, \mathrm{df}=2, p=0.112\right)$, whereas there was no significant difference in the ratio

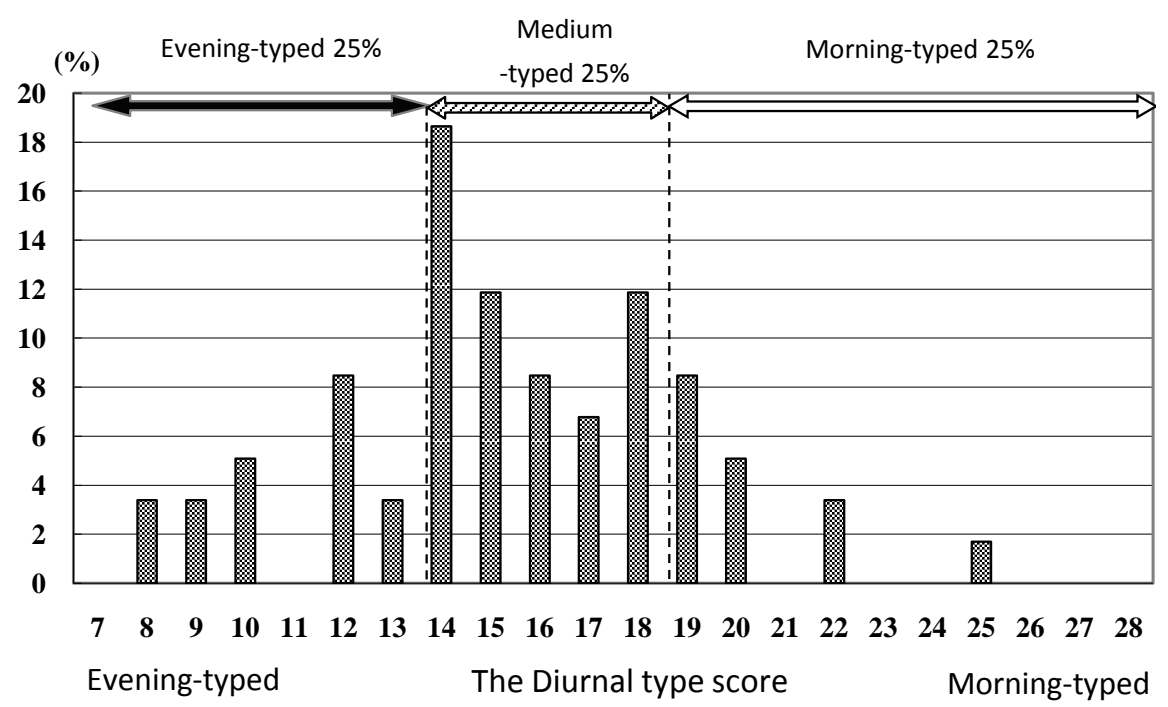

Figure 1. Distribution of the Diurnal Type Score constructed by Torsvall \& Åkerstedt (1980) shown by Japanese university soccer club members (all males).

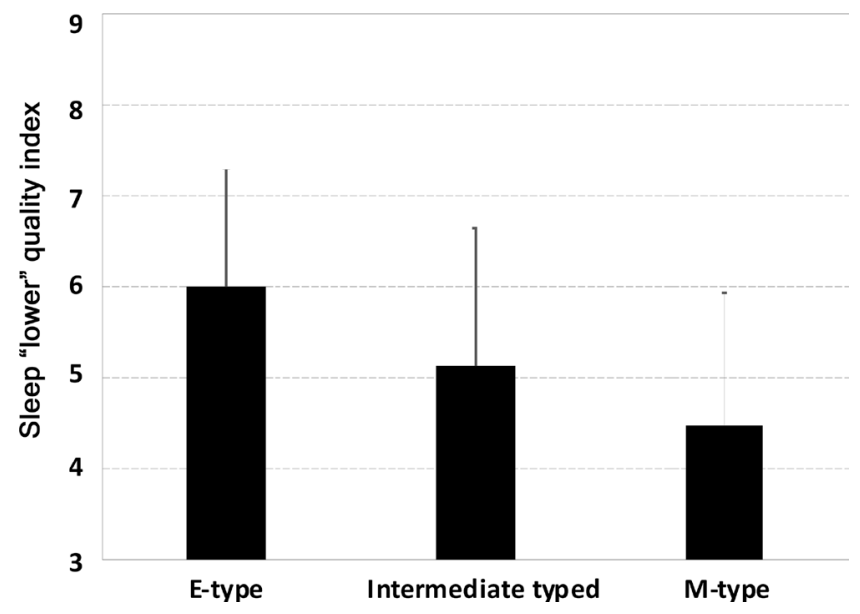

Figure 2. Chronotype and sleep quality index shown by Japanese university soccer club members (all males). 


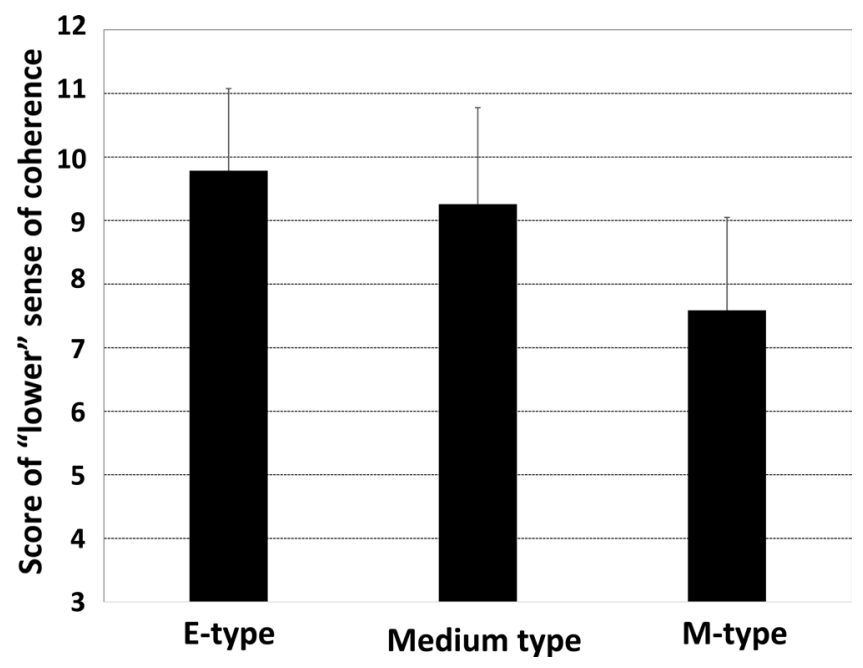

Figure 3. Chronotype and scores on sense of coherence shown by Japanese university soccer club members (higher scores with worse condition) (all males).

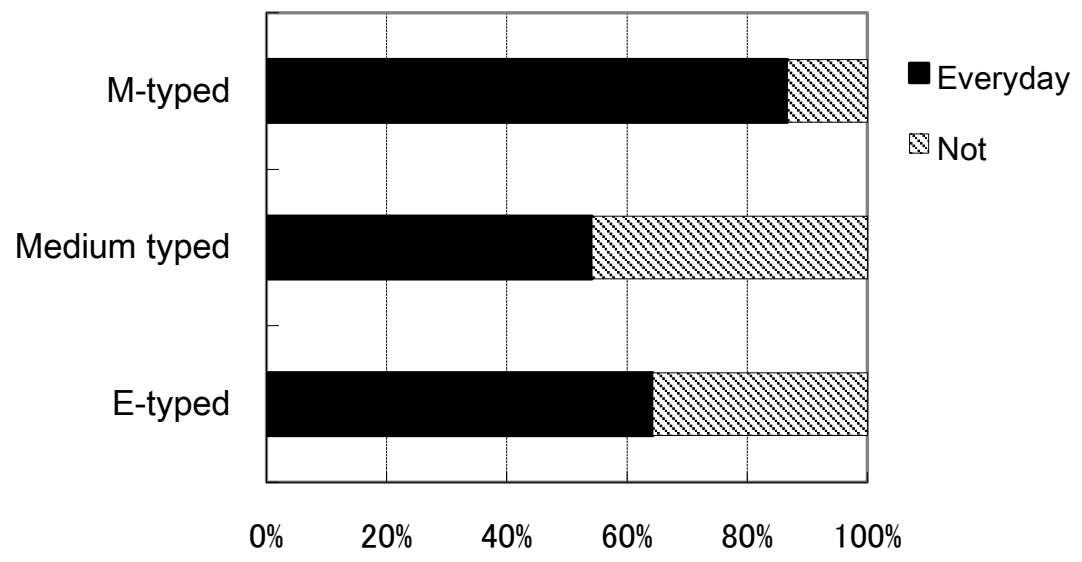

Figure 4. Relationship between chronotype and whether taking breakfast everyday or not in Japanese university soccer club members (all males).

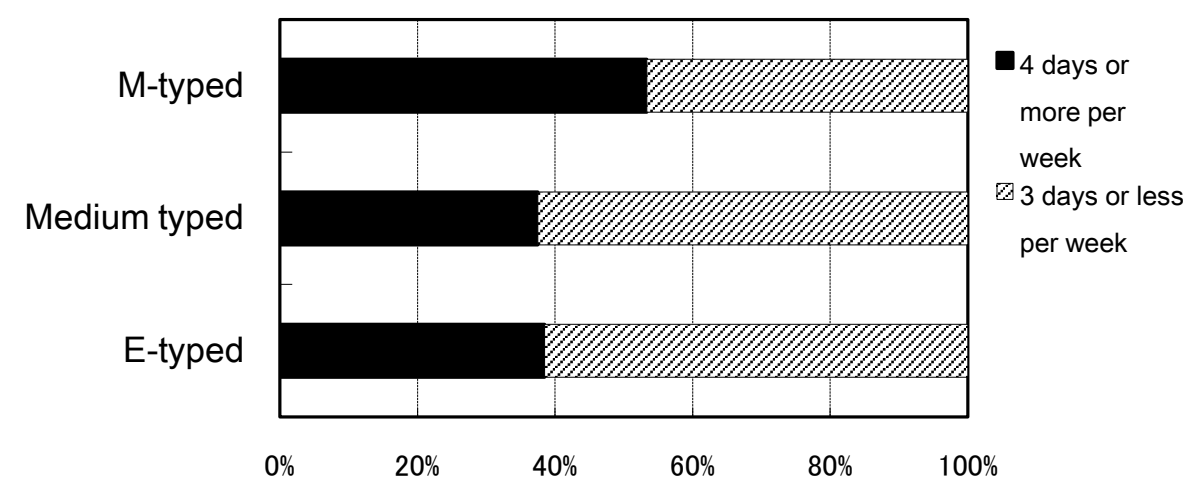

Figure 5. Relationship between chronotype and the frequency to take a nutritionally rich breakfast including staple diet, main dish and side dish in Japanese university soccer club members.

to take breakfast with "nutritionally rich breakfast" including stable (carbohydrate), main dish (protein) and side dish (vitamins and minerals) among the three chrono-types tended to be higher in the morning-typed group than the other two groups $\left(\chi^{2}\right.$-test, $\chi^{2}$-value $=1.053, \mathrm{df}=2, p=0.591$ ) (Figure 4 and Figure 5). 
There were no significant differences in the ratio of participants to eat refreshments between meals and to take beverage (excluding water, tea and coffee) among the three chrono-types $\left(\chi^{2}\right.$-test, refreshments: $\chi^{2}$-value $=2.188$, $\mathrm{df}=4, p=0.701$; beverage: $\chi^{2}$-value $=5.634, \mathrm{df}=4, p=0.228$ ). Although there were no significant differences in the amount of carbohydrate to be taken at meals due to the small number of participants, the morning-typed tended to take lower amount of carbohydrates at meals than the evening-typed one (Table 1). Evening-typed university athletes took more amount of confectionery and sweet beverage than morning-typed ones (KruskalWallis test, confectionery: $\chi^{2}$-value $=7.54, \mathrm{df}=2, p=0.023$; beverage: $\chi^{2}$-value $=9.46, \mathrm{df}=2, p=0.009$ ) (Figure 6 and Figure 7).

Table 1. Chronotype and carbohydrates consumed per day by Japanese athletes.

\begin{tabular}{|c|c|c|c|c|c|c|}
\hline \multirow{2}{*}{\multicolumn{2}{|c|}{ ME-3 type }} & \multirow{2}{*}{ Carbohydrate $^{*}$} & \multicolumn{4}{|c|}{ Carbohydrate (grains ${ }^{* *}$ ) } \\
\hline & & & Breakfast & Lunch & Supper & In total \\
\hline \multirow{3}{*}{ Evening-type } & mean & 279.3 & 50.1 & 59.8 & 58.5 & 168.4 \\
\hline & $\mathrm{n}$ & 12 & 12 & 12 & 12 & 12 \\
\hline & s.d & 67.2 & 22 & 23.6 & 26.5 & 64.6 \\
\hline \multirow{3}{*}{ Medium-type } & mean & 264.3 & 46.6 & 47.8 & 54.1 & 148.5 \\
\hline & $\mathrm{n}$ & 25 & 25 & 25 & 25 & 25 \\
\hline & s.d & 90 & 23.8 & 22.9 & 26.2 & 68.9 \\
\hline \multirow{3}{*}{ Morning-type } & mean & 221.1 & 42.8 & 50.5 & 45.3 & 138.5 \\
\hline & $\mathrm{n}$ & 17 & 17 & 17 & 17 & 17 \\
\hline & s.d & 73.4 & 26 & 26.9 & 27.5 & 71 \\
\hline \multicolumn{2}{|c|}{ Kruskal Wallis test $(p)$} & 0.46 & 0.682 & 0.131 & 0.294 & 0.7 \\
\hline
\end{tabular}

Carbohydrate amount in total per day (g) ${ }^{*}$, Carbohydrate taken as Grains ${ }^{* *}$ : Rice, bread and nodules (g).

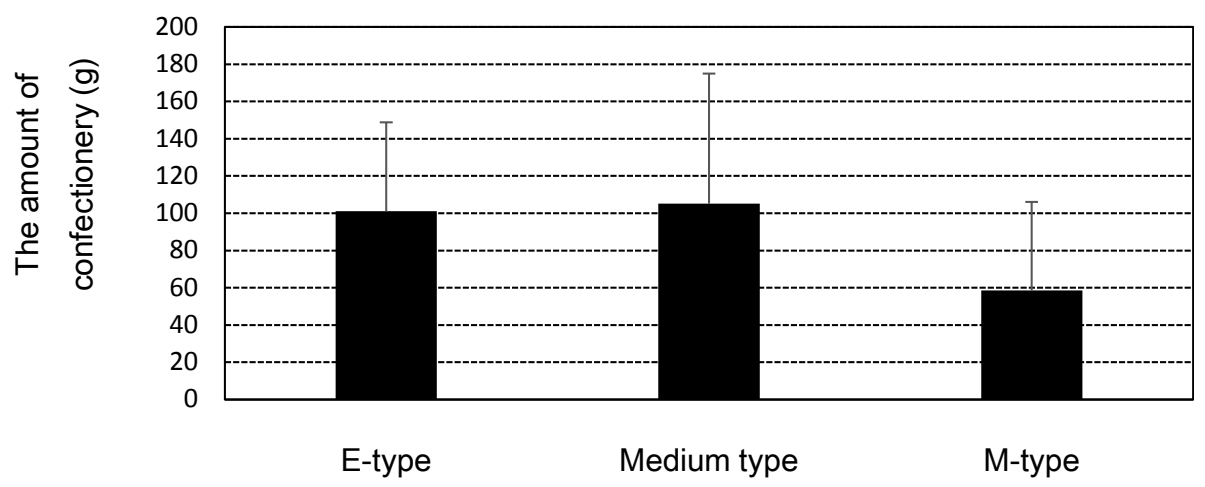

Figure 6. Relationship between chronotype and the amount of confectionery per day consumed by Japanese university soccer club members.

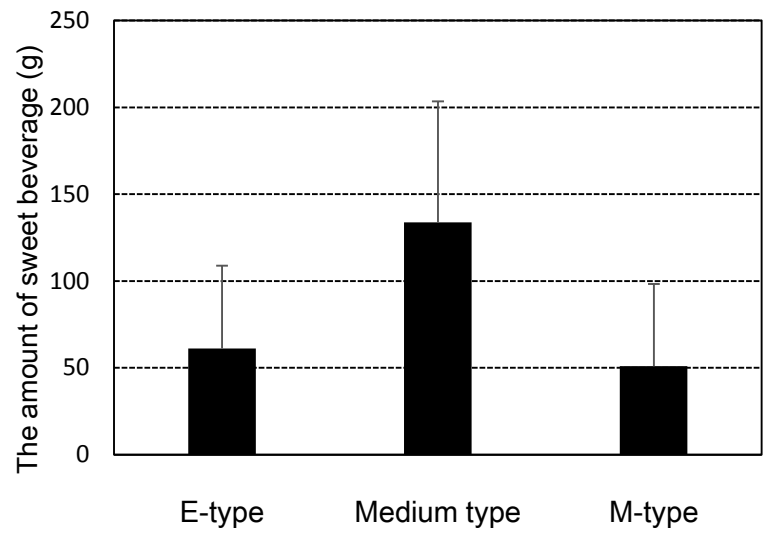

Figure 7. Relationship between chronotype and the amount of beverage (excluding water and teas) consumed by Japanese university soccer club members. 


\section{Discussion}

Evening-typed life would lead to worse sleep health such as longer sleep latency, interrupted sleep and difficulty to wake up. Scores of the sense of coherence (power to overcome the difficulty: feeling of adequate understanding, feeling of ability to act for solving the problems, and feeling in significant meaning) were lower in the evening-typed group than that in the morning-typed group. This lower ability of coherence sense by the evening-typed persons could show the lower hardiness to the social stress and can be related to the lower mental health due the "the eveningness" (Harada et al., 2013b). The relationship of the evening-typed athletes to higher amount of carbohydrates and higher amount of confectionery and sweet beverage consumed by them might imply that the evening-typed athletes tended to spend the night time with sweets such as cake or pastry and sweet beverage such as coke.

Training or competition will spend daily energy expenditure by $\sim 500>100$ Kcal per hour of exercise, although this extra energy depends on the weight and training intensity (Brouns, 1997). In this study, eveningtyped athletes took more carbohydrates than morning-typed ones by $13.2 \mathrm{~g}$ on average. Because most of the soccer club students have no practice after the dinner, the calories taken at night by the evening-typed athletes are not used for the training expenditure but can be used for fat synthesis.

However, as a limitation of this study, it is unknown whether the intervention to evening-typed athletes to be changed into the morning-typed can reduce the calories taken at night. Such intervention study remains for the near future.

In conclusion, morning-typed life for athletes might be recommended because calories can be taken mainly in the daytime and not used for fat synthesis but effectively for the training expenditure.

\section{Acknowledgements}

We thank all the participants of this study. Thanks are also due to the financial supports by Research Foundation by Japan Dairy Association (J-MILK) (2013-2015) (To T. Harada).

\section{References}

Brouns, F. (1997). Functional Foods for Athletes. Trends in Food Science \& Technology, 8, 358-363. http://dx.doi.org/10.1016/S0924-2244(97)01081-9

Delgado-Andrade, C., Rufián-Henares, J. A., Jiménez-Pérez, S., \& Morales, F. J. (2006). Tryptophan Determination in Milk-Based Ingredients and Dried Sport Supplements by Liquid Chromatography with Fluorescence Detection. Food Chemistry, 98, 580-585. http://dx.doi.org/10.1016/j.foodchem.2005.07.036

Harada, T., Wada, K., Kondo, A., Nakade, M., Maeda, M., Noji, T., \& Takeuchi, H. (2012). Chapter 22: Mental Health of Children from a Chronobiological and Epidemiological Point of View. In V. Olisah (Ed.), Essential Notes in Psychiatry (pp. 439-458). InTech. http://dx.doi.org/10.5772/38801

Harada, T., Nakade, M., Wada, K., Akimitsu, O., Noji, T., Krejci, M., \& Takeuchi, H., (2013a). Chapter 33: Tryptophan and Sleep: Breakfast Tryptophan Content and Sleep. In: V. R. Preedy, V. B. Patel, \& L.-A. Le (Eds.), Handbook of Nutrition, Diet and Sleep (pp. 473-487). Wageningen: Wageningen Academic Publishers.

Harada, T., Wada, K., Akimitsu, O., Krejci, M., Noji, T., Nakade, M., \& Takeuchi, H. (2013b). Epidemiological Evaluation of Intervention Program to Promote Mental and Sleep Health of Sports Athletes. International Journal of Psychological Studies, 5, 155-168. http://dx.doi.org/10.5539/ijps.v5n3p155

Portaluppi, F., Smolensky, M. H., \& Touitou, Y. (2010). Ethics and Methods for Biological Rhythm Research on Animals and Human Beings. Chronobiology International: The Journal of Biological and Medical Rhythm Research, 27, 19111929. http://dx.doi.org/10.3109/07420528.2010.516381

Rufián-Henares, J. A., Delgado-Andrade, C., Jiménez-Pérez, S., \& Morales, F. J. (2007). Assessing Nutritional Quality of Milk-Based Sport Supplements as Determined by Furosine. Food Chemistry, 101, 573-578. http://dx.doi.org/10.1016/j.foodchem.2006.02.016

Ryan-Krause, P. (1998). The Score on High-Tech Sports Nutrition for Adolescents. Journal of Pediatric Health Care, 12, 164-166. http://dx.doi.org/10.1016/S0891-5245(98)90251-6

Takeuchi, H., Wada, K., Kawasaki, K., Krejci, M., Noji, T., Kawada, T., Nakade, M., \& Harada, T. (2014). Effects of Cow Milk Intake at Breakfast on the Circadian Typology and Mental Health of Japanese Infants Aged 1 - 6 Years. Psychology, 5, 172-176. http://dx.doi.org/10.4236/psych.2014.52027

Torsvall, M. D., \& Åkerstedt, T. A. (1980). A Diurnal Type Scale: Construction, Consistency and Validation in Shift Work. 
Scandinavian Journal of Work \& Environmental Health, 6, 283-290. http://dx.doi.org/10.5271/sjweh.2608

Wada, K., Nakade, M., Takeuchi, H., Noji, T., \& Harada, T. (2010). Effects of Intervention as Introduction to Taking Protein and Vitamin Rich Breakfast and Following Sun-Light Exposure on Sleep and Mental Health of Japanese University Soccer Team Members Inhabiting Kochi Prefecture. Journal of Japan Society of Physiological Anthropology, 15, 97-103.

Wada, K., Yata, S., Akimitsu, O., Krejci, M., Noji, T., Nakade, M., Takeuchi, H., \& Harada, T. (2013). A Tryptophan-Rich Breakfast and Exposure to Light with Low Color Temperature at Night Improve Sleep and Salivary Melatonin Level in Japanese Students. Journal of Circadian Rhythms, 11, 4. 
Appendix 1: The Diurnal Type Scale (DTS) Constructed by Torsvall \& Åkerstedt (1980)

1. When would your child prefer to rise (provided you have a full day's study or activity) if you were totally free to arrange your time?
(4) before 06:30
(3) $06: 30-07: 29$
(2) $07: 30-08: 29$
(1) $08: 30$ or later

2. When would you prefer to go to bed (provided you have a full day's study or activity $8 \mathrm{~h}$ ) if you were totally free to arrange your time?
(4) before 21:00
(3) 21:00-21:59
(2) 22:00-22:59
(1) 23:00 or later

3. If you always had to go to bed at 21:00, what do your chil think it would be like to fall asleep then?
(4) easy - would fall asleep practically at once
(3) rather easy - would like awake for a short time
(2) rather difficult - would like awake for some time
(1) very difficult - would lie awake for a long time

4. If you always had to rise at 06:00, what do you think it would be like to get up then?
(4) easy - no problem at all
(3) a little unpleasant but not great problem
(2) rather difficult and unpleasant
(1) very difficult and unpleasant

5. When do you usually begin to feel the first signs of tiredness and need for sleep?
(4) before 21:00
(3) 21:00-21:59
(2) 22:00-22:59
(1) $23: 00$ or later

6. How long a time does it usually take before you "recover your faculties" in the morning after rising from a night's sleep?
(4) 1 - 10 min
(3) 11 - 20 min
(2) 21 - 40 min
(1) more than $40 \mathrm{~min}$

7. Please indicate to what extent you are a morning or evening active individual.
(4) pronounced morning active (lie, morning alert and evening tired)
(3) to some extent morning active
(2) to some extent evening active (lie, morning tired and evening alert)
(1) pronounced evening active

\section{Appendix 2: Questions on Sleep Quality (Rich Sleep Type-Poor Sleep Type) (GPS Score)}

1. How many minutes does it take for you to fall in sleep after the bed time? About minutes

2. How many times is your night sleep interrupted spontaneously?
( ) Never
( )
times on average per night

3. How smooth is your "falling-in-sleep"? Please judge the level of smoothness (quickly or taking long time) of your falling-in-sleep as a choice from 5 ones. (Please mark the circle)

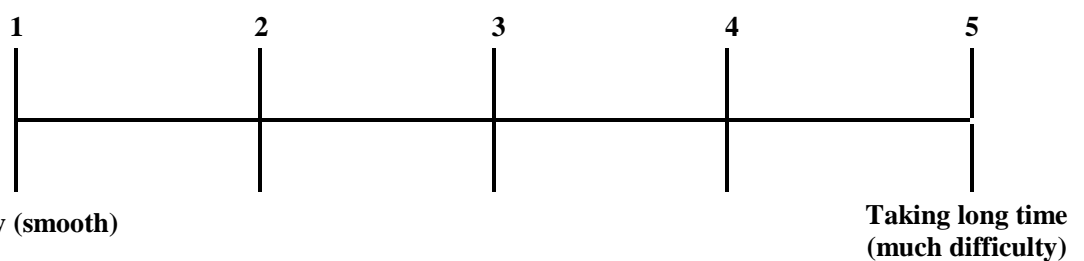

\section{Appendix 3: University of Tokyo Health Sociology Version of the Sense of Coherence (SOC3 UTHS)}

\section{(Scores were distributed from 3 to 21 and higher scores with worse condition.)}

Please mark circle on one from 7 choices which is appropriate for you as the answer to the following Three questions to you.

Question 1: Do you find out the ways to solve the problems (or difficulties) which occur in usual life?

\section{$\begin{array}{lllllllll}\text { Fulfill } & 1 & 2 & 3 & 4 & 5 & 6 & 7 & \text { Not at all }\end{array}$}

Question 2: Do you think that some of the problems and difficulties which occur in your life are worthy to be faced and to be tried by you to solve?

$\begin{array}{llllllllll}\text { Fulfill } & 1 & 2 & 3 & 4 & 5 & 6 & 7 & \text { Not at all }\end{array}$

Question 3: To how extent do you predict and understand the problems and difficulties which occur in your usual life?

$$
\begin{array}{lllllllll}
\text { Fulfill } & 1 & 2 & 3 & 4 & 5 & 6 & 7 & \text { Not at all }
\end{array}
$$

